\title{
Inequitable Access to Healthcare in Africa: Reconceptualising the "Accountability for Reasonableness Framework" to Reflect Indigenous Principles
}

Samuel Jonathan Ujewe ( $\sim$ sujewe@yahoo.com )

Global Emerging Pathogens Treatment Consortium (GET-Africa) https://orcid.org/0000-0002-8554-9400

Werdi C. van Staden

University of Pretoria Faculty of Health Sciences

\section{Research Article}

Keywords: Health equity, Justice as fairness, Communal Responsibility, Process, Solidarity, Sub-Saharan Africa, Healthcare context

Posted Date: February 19th, 2021

DOI: https://doi.org/10.21203/rs.3.rs-211469/v1

License: () (1) This work is licensed under a Creative Commons Attribution 4.0 International License. Read Full License 


\section{Abstract}

Background

The "Accountability for Reasonableness" (A4R) framework has been widely adopted in working towards equity in health for sub-Saharan Africa. Its suitability for equitable health policy in Africa hinges, at least in part, on its considerable successes in the United States and it being among the most comprehensive ethical approaches in current literature in addressing inequitable access to healthcare.

Methodology/Finding

This article considers applications of A4R towards health equity in sub-Saharan Africa - including the WHO's "3-by-5" and the REACT projects - and ascribes some of the challenges that these projects encountered to an incongruity between the underpinning ethical principle of $A 4 R$ and the communitarian ethical principle dominant in sub-Saharan Africa. These are respectively the fair equality of opportunity principle derived from John Rawls' theory, and the African communal responsibility principle.

Conclusion

A health equity framework informed by the latter, we contend, should be more suitable for African contexts, generating impetus from within Africa alongside the affordances of A4R.

\section{Introduction}

This article takes issue with the suitability of Norman Daniels' ethical approach to equity in healthcare, as summed up in the "Accountability for Reasonableness" (A4R) framework (Daniels, 2007), towards effective policy reforms and equitable access to healthcare in sub-Saharan Africa. It argues that a more suitable equity framework of effective and substantive reach should engage with the ethic of communal responsibility dominant in sub-Saharan Africa. Daniels' ethical approach is arguably the most utilised equity approach towards improving fairness or equitable access to healthcare in Sub-Saharan (Ujewe, 2016). His approach has been largely adopted owing to, at least in part, its considerable use to inform healthcare reforms in the United States (DANIELS, Daniels and Light, 1996), and its adoption in the World Health Organisation (WHO) health improvement programs (Daniels, 2007). This has been taken up by adapting the framework towards equitable healthcare reforms in low-and-middle-income-countries (Daniels et al., 2000, 2005; World Health Organization, 2004; Daniels, 2007).

Specifically, the application of A4R in sub-Saharan Africa has met with various challenges. This raises concerns regarding the contextual limitations and suitability of the equity framework for Africa-specific healthcare reforms. Despite the numerous approaches being adopted by African countries towards equalizing healthcare, access to quality services remains significantly low or non-existent for much of the populations (Ujewe, 2016; WHO, 2020). This results in avoidable inequity in access to healthcare across population groups, as those who can afford private healthcare or health insurance get what they want, and those who cannot afford these do without even basic healthcare (Arin and Hongoro, 2013; Akuki, 2015; Patel, 2017; Writer, 2017; Ujewe, 2019).

While the socio-economic dimensions of equity drives healthcare improvement initiatives (Harris et al., 2011; Langlois et al., 2015; Asante et al., 2016; Heaton et al., 2016; Pettigrew and Mathauer, 2016), some health reform initiatives in the past two decades have been driven by the A4R framework, including the WHO "3-by-5" program and the REACT (Response to Accountable Priority-Setting for Trust in Health Systems) project in East Africa (Daniels, 2007; Byskov et al., 2014). Also, A4R has recently been adopted and applied in a clinical setting in South Africa towards improving equity in access to dialysis (Moosa et al., 2016). While these point to the potential value of AFR in sub-Saharan African contexts, it is important to note that these adaptations have so far not critiqued the foundational principles of A4R and seem to proceed with a priori conviction of its adaptability, given its prior success in the American context.

However, that an approach has been successful in some contexts does not always imply similar success in others. The Structural Adjustment Programs (SAPs), introduced in the 1980s, was peached to enhance healthcare equity in sub-Saharan Africa, but became grossly inadequate for the contexts. SAPs was proposed by high-income donor countries and designed by the International Monetary Fund (IMF) and the World Bank (WB) (Logie and Woodroffe, 1993). The package included trade liberalisation, currency devaluation, removal of government subsidies and price control, and cost recovery in healthcare and education. The introduction of SAPs led to a marked depression in health status marked by increased food insecurity and malnutrition, rising prevalence of ill health, and a decrease in access to healthcare in more than two-thirds of Sub-Saharan African (SAA) countries (Kanji, Kanji and Manji, 1991; Riddell, 1992; Loewenson, 1993; Peabody, 1996; Geo-Jaja and Mangum, 2001; Coburn, Restivo and Shandra, 2015).

Although SAPs was strategically designed to improve the conditions of poor countries, the negative effects, especially widening inequity in healthcare, shows that an externally generated strategy may not always be successful in navigating local conditions. The theorisation of SAPs may have been adequate and logically sound; yet its application in SAA was fraught with fatal consequences. The failure of SAPs is partly a function of discord between design and context - although a SAA initiative, was conceptualised and designed from outside of SAA contexts. Its application was marred by contextual limitations, leading to its failure. Adapting A4R towards enhancing healthcare equity in SAA contexts needs to be reassessed in terms of the conceptual harmony with indigenous SAA contexts.

In this article, we draw attention to the fundamental ethical aspects that underpin and frame the pursuit of healthcare equity in Africa. We note that A4R has conceptual limitations that undermine its suitability for SAA contexts, despite its notable contributions to healthcare in the United States. We argue that an equity framework underpinned by African communitarian ethical principles may be more suitable, as it generates impetus from within the continent. We ascribe some of the challenges encountered in applying A4R in SAA to an incongruity between its underpinning ethical principle and the communitarian ethical principle dominant in the continent. These are, respectively: the fair equality of opportunity principle, and the communal responsibility principle. We do

Page 2/11 
not aim to address questions of Western hegemony in bioethics, nor do we intend to belittle Daniels' ingenious contribution. Rather, we revisit applications of A4R in SAA and provide reason to consider Africa-specific ethical approaches to address issues of healthcare equity.

Throughout this article, we use the term African in a similar sense as Godfrey Tangwa:

There is a great variety and diversity between the different African ethnicities, but they are all united by commonalities that give them a remarkable family resemblance analogous to the family resemblance of groupings that are in some ways remarkably different from one another but all justifiably bracketed under the term Western. (Tangwa, 2017, p. 104)

Also, we use the term community to refer not only to locatable groups of people living in small villages across SAA. Instead, community entails both geographically locatable groups and groups of persons linked through societal structures, including governmental and non-governmental agencies.

\section{Methodology}

\section{Accountability for Reasonableness (A4R)}

A4R refers to the idea that the reasons or rationales for important limit-setting decisions to enhance equity in healthcare should be publicly available and accessible, and that these reasons must be ones that fair-minded people can agree are relevant for pursuing relevant care where resources are limited. It requires that the public not only have access to the decision made, but also the reasons underlying these decisions, and accept these as relevant towards providing high quality and equitable care for them (Daniels and Sabin, 2008). The A4R framework is a practical tool that provides guidance to ensure fairness and equity in health decision-making processes. It aims to ensure that in a pluralist society, where reasonable disagreement about principles that should guide equitable health policy are likely, a fair process will help to establish acceptable decisions. This is laid out in four arms referred to as the four conditions, namely: publicity, relevance, appeal and revision, and regulative (Daniels, 2007; Gruskin and Daniels, 2008).

\section{Publicity Condition}

This requires that the rationale for decisions guiding the equitable distribution of healthcare resources or services be made publicly available, and accessible to those who may wish to raise objections or suggest alternative considerations (Daniels and Sabin, 1997). It aims to ensure transparency in healthcare or policy decision processes, as "decisions regarding both direct and indirect limits to care and their rationales must be made publicly accessible" (Daniels and Sabin, 2008, p. 45). One basic principle is that similar cases should be treated similarly and that differential treatments must be justified by relevant reasons, the consistency of which will overtime convince people of the moral commitments of the institutions making them (Daniels and Sabin, 2008).

\section{Relevance Condition}

It requires that the reasoning guiding decision-making for equity in healthcare and reforms are explainable to every reasonable person.

The rationales for priority-setting decisions should aim to provide a reasonable explanation of why the priorities selected were determined to be the best approach... a rationale is reasonable if it appeals to evidence, reasons, and principles accepted as relevant by fair-minded people. (Gruskin and Daniels, 2008, p. 1576).

Under this condition, it should be possible for the concerned population to understand and accept the reasoning behind a particular health service fee, for instance. The kind of rationales provided should aim to provide a reasonable explanation on how any healthcare decision arrived at seeks to offer value for money. Is not sufficient to simply specify the goals, the goals must also appeal to reason, including values and principles that are acceptable to the concerned population (Daniels and Sabin, 2008).

\section{Appeals and Revision Condition}

This provides a mechanism for challenging and disputing decisions in healthcare, and provides opportunities for revision and improvement in the light of new evidence or questions (Gruskin and Daniels, 2008). It plays three distinctive roles

- offering citizens a form of due process by which to attempt to revise adverse effects of inequitable healthcare decisions;

- giving those who are affected the opportunity to present their views towards improving decisions; and

- educating society about the need for setting limits for equity in healthcare through fair resource allocation decisions. (Daniels, 2007)

These hinge on the ground that healthcare decisions remain open to contestations to ensure that good arguments against the original decision can provided a fair route back into the policy decision process, and those affected by it can engage in the process (Daniels and Sabin, 2008)

\section{Regulative Condition}

This requires the establishment of voluntary, public or legal strategies to ensure that the publicity, relevance and appeals conditions are met (Daniels, 2007). It affords the population a structure that ensures equity in healthcare, where their needs are prioritised in the decision-making process.

Thus, A4R constitutes a rational process that helps all stakeholders to understand the justification for (not) limiting certain services to some population groups, for instance, in order to enhance health equity. It ensures that policy decisions or interventions strategies are acceptable to all, at least in principle. The 
four conditions build on each other in determining the legitimacy of healthcare decision-making processes, so that satisfying all but one condition may not be sufficient in establishing health equity.

\subsection{Conceptual Underpinnings of A4R}

A4R hinges on a conceptual framework underpinned by the three moral questions for health, referred to as the three focal questions (Daniels, 2007):

1. Is health of special moral importance?

2. When are health inequalities unjust?

3. How can we meet health needs fairly under resource constraints? (Daniels, 2007)

The focal questions address three basic explanations underpinning A4R. An appropriate response to these questions will constitute an equity framework healthcare and offer practical ethical guidance toward policy reforms (Daniels, 2007). Addressing the first focal question establishes the significance of health in ways that justify why societies should distribute healthcare resources more equitably than other social goods. The second question accounts for the many socially controllable factors, beside access to healthcare, that affect levels of population health and degrees of health equity within a system and between systems. And in addressing the third question, society stipulates the terms of fair process for making rationing decisions in distributing healthcare resources to the benefit of all. (Daniels, 2007)

Response to the focal questions provides a conceptual basis for pursuing justice in healthcare, identifies evidence of health inequalities that raise questions of justice, and offer pathways towards reforms for equity in healthcare. The framework helps society to examine the broader institutional setting and policies that mediate a population's health, clarifying when a health inequality is unjust; what counts as a reasonable progress in reducing health inequality; and tests these in the context of actual policy choices. More importantly, it helps to develop a general account of fair process to legitimise decision-making processes. (Daniels, 2001)

Thus considered, the A4R approach presents great potential towards addressing equity questions surrounding the distribution of healthcare in Africa. It promises to inform substantive health system reforms, while legitimising the policy making process. It also establishes the obligation of health service providers to guarantee access, grant healthcare users the capacity to demand available services and hold policy makers accountable.

\section{Result}

\section{Challenges to A4R's Applications in Africa}

While the A4R framework has been widely accepted and implemented in various health policy processes in the United States (DANIELS, Daniels and Light, 1996; Daniels and Sabin, 1997, 2008; Daniels, Kennedy and Ichiro Kawachi, 2000; Daniels, Kennedy and Ichirō Kawachi, 2000; Daniels, 2001, 2007; Neumann et al., 2008), it also attracted interest in healthcare reforms and intervention in Africa. Notable among these are is use in the: WHO "3-by-5" project (Macklin, 2004; World Health Organization, 2004; Daniels, 2005, 2007); and REACT project (Mshana et al., 2007; Maluka, Kamuzora, San Sebastián, et al., 2010; Maluka, Kamuzora, San Sebastiån, et al., 2010; Maluka, 2011; Maluka et al., 2011; Byskov et al., 2014). Both of these projects adopted the A4R framework as the equity platform on which to base targeted distribution of healthcare for specific population groups.

\subsection{The WHO's 3-by-5 Program}

The WHO's 3-by-5 program was an initiative to scale up equitable distribution of anti-retroviral (ARVs) drugs and other HIV-related treatments, which set out to treat 3 million HIV/AIDS patients by the year 2005. Malawi, Tanzania, Ethiopia, and South Africa were some of the countries that featured in the project. Three key ethical guidelines of the 3-by-5 program include: firm reference for public discussion; a process that is fair to all; and results that are ethically sound. The need for fair process in the 3-by-5 program was considered essential for patient selection, given the lack of a specific principled approach at the time (Daniels, 2005). The A4R framework informs the four equity aspects of the program:

1. Cost-recovery for drugs and services: Despite reasonable disagreements about what principles should guide the funding, the final decision hinged on the kind of reasons on which all could agree for the provision of free ARV treatments

2. Medical eligibility criteria: Recommendation to consider best outcomes in the distribution of scarce medical resources, thereby extending the program to benefit the sickest patients

3. Location of treatment facilities: Guided by the principle of fairness, the program aimed to balance the distribution of treatment facilities to cover a wide proportion of the population, as well as reach those most in need, and

4. Priority to special groups: Guidelines were set to balance priority concerns between health workers who are most at risk of HIV infection and the sickest HIV/AIDS patients, and similar value disagreements. (Daniels, 2005, 2007)

Considerations of fairness were observed in the decision-making process, Daniels notes, as several value disagreements were mitigated through the fair deliberative process. The process allowed room for counter cases to be raised, and allowed initial decisions to be revised in the light of further evidence (Daniels, 2005). Hence, the key aspects of the 3-by-5 program reflect the four conditions of the A4R framework.

\subsection{The REACT Project in Tanzania}

Whereas the 3-by-5 program was an externally developed initiative introduced to Africa, the REACT project was internally developed and deployed to enhance equity in access to healthcare among local populations. One key aspect of REACT was its adaptation of the A4R framework into health system reform processes in rural Tanzania (Mshana et al., 2007; Maluka, Kamuzora, San Sebastián, et al., 2010; Maluka, Kamuzora, San Sebastiån, et al., 2010; Maluka, 2011). 
The project's strategy involved describing existing policy practices in healthcare and supplementing them with the A4R framework to enhance effectiveness in the design and implementation processes. An evaluation of the REACT project showed that adapting A4R towards health system reform in Tanzania had wide appeal to both policy makers and the population for the following reasons:

1. It involved multiple stakeholders to ensure that relevant values of affected communities were considered

2. It informed the population about the rationale behind set priorities to create greater transparency, and enabled communities to know how healthcare resources were allocated, and

3. It provided a mechanism for appeal to enable communities to express their dissatisfaction about some decisions. (Maluka, Kamuzora, San Sebastián, et al., 2010; Maluka, 2011)

\subsection{Challenges Encountered in Africa}

The 3-by-5 program was widely acclaimed for enhancing a speedy scale-up of ART in Sub-Saharan Africa. For instance, the program was shown to benefit large numbers of rural populations in Malawi, and was recommended for uptake across Africa (Ferradini et al., 2006; Libamba et al., 2007). A rapid scale-up was also recorded in Ethiopia (Assefa et al., 2009). However, several challenges were noted in the scale-up programs in different countries. In Ethiopia, it was acknowledged that HIV prevention and management of chronic care patients still posed a major concern, as the health system had yet to adopt a chronic care model linking care delivery with community-and-home-based interventions for HIV/AIDS patients (Assefa et al., 2009). In Malawi, about three quarters of those who started treatment defaulted, with half confirmed to have died shortly afterwards (Yu et al., 2007). The most prevalent reason for defaulting was the cost of transportation from home to clinic, in spite of many patients being traceable. Van Damme et al. (2006) (Van Damme, Kober and Laga, 2006) attribute the problem to an existent incapacity, coupled with the additional burden of scaling-up. They note, for instance, that the healthcare sector was largely underresourced and lacking in personnel and facilities for basic healthcare; hence including the ART roll-out program into routine healthcare posed additional challenges.

Like the A4R framework, the ethical principle underlying the 3-by-5 program focuses on individuals' benefits, without recourse to the relevant socio-ethical contexts in which healthcare is situated. Thus, the 3-by-5 program was ethically misaligned with the African contexts in which it was implemented. A viable ethical approach to equity in access would account for individuals' interests no less, but also recognise the central role of their networks of relationships and responsibilities.

In light of the application of A4R in the REACT project, specific limitations were observed for local conditions in Tanzania. Among these, Maluka (2011) (Maluka, 2011) notes the need:

1. for more engagement with affected communities in the decision-making process than the framework suggests

2. to recognize underlying power asymmetries between affected communities and policy makers, and

3. to recognize the nature of the local context's socio-cultural traditions.

Additionally, Mshana et al. (2007) (Mshana et al., 2007) observed that:

1. the ethical approach was considered by local communities as being too technical and complicated

2. many potential stakeholders might not have had the knowledge, skills or experience to effectively contribute to the process, which made some participants feel intimidated, and

3. the analytical description of relevant reasons was complex and difficult for policy makers to communicate to the relevant population.

Overall, there was inadequate understanding of the process and its mechanism for influencing legitimacy and fairness in the local Tanzanian context, as reflected in health service management processes and outcomes (Maluka et al., 2011). The first set of limitations noted in both Maluka et al. (2011) (Maluka et al., 2011) and Mshana et al. (2007) (Mshana et al., 2007) show the need to engage local meanings within the people's socio-ethical context; the second present the challenges of adopting a procedural approach that is unfamiliar to the local context; and the third presents socio-cultural challenges, as A4R does not account for local socio-cultural factors relevant to healthcare. If A4R was perceived as too technical or complex by local populations, it may not literally mean that the people simply lacked knowledge. Rather, it shows that the knowledge system underpinning A4R is different from that in the local context.

In light of the above, the challenge hinges on substantive value differences between the modes of inquiry and analysis of the local contexts and those underpinning the A4R framework. The difficulty can be ascribed to an incongruity between the underpinning principles of A4R and the dominant ethical principles in African contexts. There is need for "...a broader and more detailed analysis of ... the socio-cultural context... illuminating areas that require special attention to promote sustainability" (Maluka et al., 2011, p. 14).

\section{Discussion}

\section{Incongruity Between Underpinning Principles of A4R and African Ethics}

It is easy to attribute the challenges to A4R in African settings to technical difficulty in understanding or applying the framework. It is important to note, however, that contextual value differences and substantive variances in the principles underpinning A4R and those dominant in African ethical contexts pose a major challenge. Primarily, A4R is founded on the ethical principle of Fair Equality of Opportunity, while the principle of Communal Responsibility predominates in African ethical contexts. A more effective framework for equitable allocation of healthcare in African contexts, we contend, should crucially account for the principle of communal responsibility. 


\subsection{A4R and the Fair Equality of Opportunity Principle}

The A4R approach is premised on a functional relationship between preserving health and the kind of opportunities open to an individual in any given society. While a variety of opportunities open to individuals to pursue may depend on key economic and cultural features, and socialisation and/or historical developments of their particular societies, their physiological functioning is significant in determining the kind of opportunities they can actually pursue (Daniels, 1985):

Impairment of normal functioning through disease and disability restricts an individual's opportunity relative to that portion of the normal range his skills and talents would have made available to him were he healthy... disease and disability shrinks his share from what is fair. (Daniels, 1985, pp. 33-34)

This claim is informed by John Rawls' theory of justice as fairness, which prescribes the principle of fair equality of opportunity (FEO) as essential for equity in the distribution of social goods (Daniels, 2007). FEO is concerned with the principle that free and rational individuals in any society, each of whom are concerned to advance their own interests, would accept in an original position of equality as stipulating their basic terms of agreement (Rawls, 2001). Specifically:

1. each person would have the same indefensible claim to a fully adequate scheme of equal basic liberties, which is compatible with the same scheme of liberty for all; and

2. social and economic inequalities must be attached to offices and positions open to all, and should be of the greatest benefit to the least-advantaged members of society. (Rawls, 2001)

A4R hinges on $b$ above. FEO appeals to A4R given its potential to defend the obligation towards equity in access to healthcare. For instance, FEO would insist on fair advantage to those who are economically, socially or circumstantially less advantaged in the distribution of healthcare resources (Daniels, 2007). In other words, allowing greater access to healthcare to those who are worse off would reduce their relative social disadvantage and offer them a chance to pursue their desired and available opportunities within their society.

Considering its formulation, the FEO principle is more suited to societies that emphasise individual liberty over and above networks of social relationships. This may be typical of some societies in North America or Western Europe but is far from what predominates in most African societies. In African contexts, communitarian relationships are emphasized alongside the individual's place. African ethical contexts hinge on a principle of communal responsibility.

\subsection{African Ethic of Communal Responsibility}

The moral outlook of sub-Saharan African societies is constituted by the attribute of responsibility towards communities and individuals, which serves the welfare of both. This is in contrast to the attributes of individual opportunity with underlying right claims underpinning A4R. Gyekye (2011) articulates the difference between the ethic of rights and the ethic of communal responsibility. He notes that concern for human well-being constitutes the hub of the African axiological wheel, where this sociality or relationality prescribes an ethic of responsibility. This essentially involves individuals in social and moral roles in the form of obligations and commitments to other members of their community. In this context, the ethical values of compassion, solidarity, reciprocity, cooperation, interdependence and social well-being constitute the moral principles that impose duties on individuals with respect to the community and its members (Gyekye, 2011).

This ethics outlook differs from the rights ethic underlying A4R. Where individuals' rights are emphasised, there are no immediate moral obligations and commitments to others simply in virtue of belonging to the same community. An individual is obligated to another only insofar as the latter can make viable claims that commit the former. Conversely, the ethic of communal responsibility does not eliminate benefits due to individuals. Individuals may lay claims to their entitlements but must always be conscious of their corresponding responsibilities to others in their web of relationships. For instance, among many cultural groups in Nigeria, male or older children are entitled to larger shares of family inheritance. However, the inheritance comes with a corresponding share of responsibility towards bearing the family's burdens, including taking care of the widowed mother or wife; and the financial, educational, and other needs of younger/dependent siblings. Thus, the right to a larger share of inheritance is recognised, but always with a corresponding responsibility for the family.

By a Western account, it may be easy to assume that individuals' rights are obliterated, undermined or trumped by the kind of responsibility enjoined in African moral spheres. It is worth noting, however, that:

The communitarian ethic acknowledges the importance of individual rights, but it does not do so to the detriment of responsibilities that individual members have or ought to have toward the community or other members of the community...the communitarian moral theory considers responsibility as an important principle of morality.... (Gyekye, 1997, p. 66)

African contexts present a moral sphere of rights interwoven with responsibilities. Here, claiming some rights does not relieve persons of relevant responsibilities, either to themselves or to their network of relationships. An African approach to equity in access to healthcare would be defined not only by the right to access services, for instance; rather, emphasis would be placed on the relevant communities' (e.g., government agencies) responsibilities towards restoring the health and well-being of affected individual members. It would crucially subsist in balancing such rights with essential responsibilities. Emphasis on communal wellbeing does not and should not imply a neglect of individuals' interests. The priority is a dual responsibility in sustaining the health and wellbeing of every member, and the community as a whole.

The communal responsibility principle implies that interdependency is acknowledged in the pursuit of equitable access in African healthcare (Ujewe, 2016). It is considered morally reprehensible in African contexts, for instance, for persons to live economically superfluous lives, while their family (siblings or parents) live in abject poverty. Healthcare equity, by this principle, would seek to balance the well-being of individuals with that of others in their network of relationships. 


\subsection{The Incongruity}

The ethical underpinning of A4R hinges on the ideal of individual opportunity to provide justification for the obligations to healthcare equity. However, African ethics contexts are different, as described above. This incongruity implies that A4R is in principle misaligned to African healthcare contexts, as exemplified in the REACT case. A viable equity framework must supplant or address the conceptual limitations of A4R. It must also be premised on the ethic of communal responsibility, not solely fair equality of opportunity. This points to the significance of contextual differences and acknowledgement of the challenges they pose. While some moral principles may hold good universally and timelessly, their application in particular concrete situations must not dispense with local perspectives and contexts (Tangwa, 2001).

Adaptations of A4R to African contexts of healthcare have thus far overlooked these contextual differences, insisting on its viability as a universal ethical framework. Yet, the mark of a universally adaptable framework:

... is that it provides a clear principle of action that is sensitive to both moral agency and moral patients and that it plastically applies equally to all global communities and societies without necessarily attempting to make uniform particular rules of action or foist the particular or peculiar moral dilemmas, quandaries, obsessions and preoccupations of some on all... We need always to keep in mind the context and perspective... of particular actions or procedures. (Tangwa, 2001, p. 158)

The REACT and 3-by-5 programs do not account for the ethic of communal responsibility underpinning local contexts of healthcare, thereby limiting their successes. Potential claims of A4R's universal applicability are thus weakened. There is need for an equity framework that accounts for the local communitarian contexts of African healthcare.

Developing a framework that aligns with local socio-ethical contexts is crucial for optimal uptake and success for equity in access to healthcare. African contexts and approaches must take centre stage in developing the relevant framework. This would engender greater success in the formulation and execution of initiatives towards equitable access to healthcare. For healthcare initiatives to be effective, efficient, and fair, they must be integrated at several interconnected levels: between persons seeking and delivering healthcare, within the social network of each person, and across the trajectory of each person's life (Cloninger et al., 2014). For instance, it is not enough to develop a mechanism that provides free drugs to HIV/AIDS patients without considering their social, cultural and economic contexts, and those of their networks of relationship. To be equitable and effective, healthcare programs must be informed by these varying factors

\section{Pathway for an African Equity Framework}

In light of the above, it is crucial to map out a relevant equity framework for African contexts or reconceptualise A4R to reflect the African ethics contexts in which it is adapted. While developing the alternative approach is beyond the scope of this paper, we propose initial outlook for a viable pathway to healthcare equity in Africa. First, the framework should take seriously the ethical, social and cultural dimensions of African contexts. This cannot be overemphasised, as health and healthcare challenges are encountered within social and cultural communities. The approach must hinge on the principle of communal responsibility underpinning African ethics. Also, it would be informed by local knowledge systems to ensure effective communication and uptake among stakeholders in the decision-making process. Consideration should be given to specific social and cultural factors that were not anticipated in the original formulation A4R.

Second, the A4R approach hinges on Western analytic tradition in mainly employing the Rawlsian approach of "fair equality of opportunity". The equity framework for African healthcare would incorporate the ethic of communal responsibility, which has a different methodological approach. An analytical approach may not be equally useful when applied in contexts that appeal to other forms of problem-solving methodologies:

It is a question whether all problems that face us... can be solved by a purely analytical method .... The analytic paradigm of knowledge... is not the only one. There are other types of human knowledge... much better developed and more prominent in non-Western cultures... there are aspects of reality and human life and existence with which that [analytic] paradigm... cannot adequately deal with. (Tangwa, 2002, pp. 227-228)

Drawing from an African methodological perspective is important, as the knowledge components can make significant contributions towards addressing Africa-specific problems (Hountondji, 1997). It is imperative that an African approach is explored in developing a equity framework for healthcare in Africa. The framework will be underpinned by an African method of ethical analysis. This would involve emphasising people-centred processes, as reflected in the African ethic of communal responsibility.

Third, the African healthcare equity framework will employ an even-handed approach, accounting for varied socio-cultural factors while keeping universal phenomena in perspective. If we insist on a strictly African ethical approach, without recourse to the universal, we could lose some benefits of other useful healthcare reform initiatives:

There can be no culturally and psychologically perspective ethics without taking account of the diversity of moral lives, but there can be no ethics at all without universals, allowing a means of trying to stand aside from particulars to make meaningful ethical assessments. (Callahan, 2000, p. 38)

Thus, the framework would consider African modes of moral explanations without dismissing the fact of its existence within a moral universe. Accordingly, the framework could draw from relevant universal attributes of A4R, but at the same time emphasise the African moral outlook.

Fourth, the African ethics framework would incorporate key attributes of the ethic of responsibility: solidarity, process, reciprocity, and harmony: 
1. The solidarity attribute entails a process of self-understanding through others (Gyekye, 1996; Shutte, 2009; Metz and Gaie, 2010; Azetsop, 2011; Ujewe, 2016; Tosam et al., 2017) and individuals' personal and social responsibilities and commitments are always informed by the wellbeing of the whole community. The framework will be informed by the local population's socio-cultural understanding of moral responsibility.

2. The attribute of process emphasises the idea of becoming and existing through others (Bujo, 2001; Metz, 2007; Shutte, 2009; Ujewe, 2012; Van Staden and Fulford, 2015; Ujewe, 2016). It indicates the vital social interconnectedness through which obligations and commitments arise. The framework will reflect this societal interconnectedness in its formulation and execution.

3. The attribute of reciprocity is reflected by essential interdependencies emphasised in African settings (Cobbah, 1987; Crepaz-Keay, Fulford and van Staden, 2015; Ujewe, 2016). Communitarian interdependency means that the ill-health of one person invariably bears on the health of another. The framework will not only consider the health and wellbeing of individuals, but of whole communities.

4. The harmony attribute will ensure that the framework looks to the wellbeing of communities and individuals. Holistic restoration is of the utmost concern in African understandings of health and healthcare (Ujewe, 2016). Given that harmony is ascribed to as the greatest good in African moral thought (Tutu, 2000), restoration of individuals and communities will underpin the African healthcare equity framework.

\section{Conclusion}

In the absence of a relevant African ethical framework A4R has provided some respite in moving towards healthcare equity in Sub-Saharan Africa. Yet, a more suitable framework of effective and substantive reach should engage with and be driven by the ethic of communal responsibility dominant in sub-Saharan Africa. These attributes are lacking in A4R. Past experiences with the WHO's 3-by-5 program and the REACT project underscore the contextual limitations and shortcomings of A4R and indicate reason for developing an Africa-specific healthcare equity framework. Such framework holds promise of generating impetus from within Africa towards equity in access to healthcare, drawing on the continent's strengths, alongside the affordances of A4R. The wide sociocultural diversity in Africa means that the relevant framework must be flexible enough to allow for specific adaptations in different contexts. Some adjustments may be needed to match subtleties in the varying cultures. Nonetheless, much untapped potential lies in the development of an equity framework guided by the shared African ethic of communal responsibility.

\section{Declarations}

Ethics approval and consent to participate: No ethics approval was required as the study involved a conceptual analysis of secondary data

\section{Consent for publication: NA}

Availability of data and material: NA

Competing interests: There are no competing interest

\section{Funding: NA}

Authors' contributions: First author conceptualised the paper, wrote the first and revised the final drafts; second author provided insights on the conceptualization and contributed in structuring and writing the paper.

Acknowledgements: The paper is partly an output of a doctoral research conducted at the University of Central Lancashire, Preston, United Kingdom, and further developed during a postdoctoral research fellowship at the University of Pretoria, South Africa.

\section{References}

Akuki, A. (2015) 'Salvaging Nigeria's health care challenges', Independent Nigeria, 20 January. Available at: https://independent.ng/salvaging-nigerias-healthcare-challenges/ (Accessed: 20 December 2017).

Arin, D. and Hongoro, C. (2013) 'Scaling up national health insurance in Nigeria: learning from case studies of India, Colombia, and Thailand', Washington, DC: Futures Group Health Policy Project.

Asante, A. et al. (2016) 'Equity in health care financing in low-and middle-income countries: a systematic review of evidence from studies using benefit and financing incidence analyses', PloS one, 11(4), p. e0152866.

Assefa, Y. et al. (2009) 'Rapid scale-up of antiretroviral treatment in Ethiopia: successes and system-wide effects', PLoS medicine, 6(4), p. e1000056.

Azetsop, J. (2011) 'New directions in African bioethics: ways of including public health concerns in the bioethics agenda', Developing world bioethics, 11(1), pp. 4-15.

Bujo, B. (2001) Foundations of an African Ethic: Beyond the Universal Claims of Western Morality. New York: The Crossroad Publishing Company.

Byskov, J. et al. (2014) 'The accountability for reasonableness approach to guide priority setting in health systems within limited resources-findings from action research at district level in Kenya, Tanzania, and Zambia', Health research policy and systems, 12(1), p. 49.

Callahan, D. (2000) 'Universalism \& particularism: Fighting to a draw', Hastings Center Report, 30(1), pp. 37-44. 
Cloninger, C. R. et al. (2014) 'A time for action on health inequities: foundations of the 2014 Geneva declaration on person-and people-centered integrated health care for all', International Journal of Person Centered Medicine, 4(2), p. 69.

Cobbah, J. A. (1987) 'African values and the human rights debate: an African perspective', Human Rights Quarterly, pp. 309-331.

Coburn, C., Restivo, M. and Shandra, J. M. (2015) 'The African Development Bank and women's health: A cross-national analysis of structural adjustment and maternal mortality', Social science research, 51, pp. 307-321.

Crepaz-Keay, D., Fulford, K. and van Staden, W. (2015) 'Putting both a person and people first: interdependence, values-based practice and African Batho Pele as resources for co-production in mental health', The Oxford handbook of psychiatric ethics, pp. 60-84.

DANIELS, D., Daniels, N. and Light, D. (1996) Benchmarks of fairness for health care reform. Oxford University Press, USA.

Daniels, N. (1985) Just health care. Cambridge University Press.

Daniels, N. et al. (2000) 'Benchmarks of fairness for health care reform: a policy tool for developing countries', Bulletin of the World Health Organization, 78(6), pp. $740-750$.

Daniels, N. (2001) 'Justice, health, and healthcare', American Journal of Bioethics, 1(2), pp. 2-16. doi: 10.1162/152651601300168834.

Daniels, N. et al. (2005) 'An evidence-based approach to benchmarking the fairness of health-sector reform in developing countries', Bulletin of the World Health Organization, 83(7), pp. 534-540.

Daniels, N. (2005) 'Fair process in patient selection for antiretroviral treatment in WHO's goal of 3 by 5', The Lancet, 366(9480), pp. 169-171.

Daniels, N. (2007) Just health: meeting health needs fairly. Cambridge University Press.

Daniels, N., Kennedy, B. and Kawachi, Ichirō (2000) Is inequality bad for our health? Beacon Press.

Daniels, N., Kennedy, B. and Kawachi, Ichiro (2000) 'Justice is good for our health', Boston Review, 25(1), pp. 4-19.

Daniels, N. and Sabin, J. (1997) 'Limits to health care: fair procedures, democratic deliberation, and the legitimacy problem for insurers', Philosophy \& public affairs, 26(4), pp. 303-350.

Daniels, N. and Sabin, J. E. (2008) Setting limits fairly: learning to share resources for health. Oxford University Press.

Ferradini, L. et al. (2006) 'Scaling up of highly active antiretroviral therapy in a rural district of Malawi: an effectiveness assessment', The Lancet, 367(9519), pp. 1335-1342.

Geo-Jaja, M. A. and Mangum, G. (2001) 'Structural adjustment as an inadvertent enemy of human development in Africa', Journal of Black Studies, 32(1), pp. 30-49.

Gruskin, S. and Daniels, N. (2008) 'Process is the point: justice and human rights: priority setting and fair deliberative process', American Journal of Public Health, 98(9), pp. 1573-1577.

Gyekye, K. (1996) African cultural values: An introduction. Sankofa publishing company.

Gyekye, K. (1997) Tradition and modernity: Philosophical reflections on the African experience. Oxford University Press.

Gyekye, K. (2011) 'African Ethics', in Zalta, E. N. (ed.) The Stanford Encyclopedia of Philosophy. Fall 2011. Metaphysics Research Lab, Stanford University. Available at: https://plato.stanford.edu/archives/fall2011/entries/african-ethics/ (Accessed: 2 January 2018).

Harris, B. et al. (2011) 'Inequities in access to health care in South Africa', Journal of public health policy, 32(1), pp. S102-S123.

Heaton, T. B. et al. (2016) 'Social inequality and children's health in Africa: a cross sectional study', International journal for equity in health, $15(1)$, p. 92.

Hountondji, P. J. (1997) Endogenous knowledge: Research trails. African Books Collective.

Kanji, Najmi, Kanji, Nazneen and Manji, F. (1991) 'From development to sustained crisis: structural adjustment, equity and health', Social science \& medicine, 33(9), pp. 985-993.

Langlois, É. V. et al. (2015) 'Inequities in postnatal care in low-and middle-income countries: a systematic review and meta-analysis', Bulletin of the World Health Organization, 93(4), pp. 259-270G.

Libamba, E. et al. (2007) 'Malawi's contribution to" 3 by 5": achievements and challenges', Bulletin of the World Health Organization, 85(2), pp. 156-160.

Loewenson, R. (1993) 'Structural adjustment and health policy in Africa', International Journal of Health Services, 23(4), pp. 717-730.

Logie, D. E. and Woodroffe, J. (1993) 'Structural adjustment: the wrong prescription for Africa?', BMJ: British medical journal, 307(6895), p. 41. 
Macklin, R. (2004) 'Ethics and equity in access to HIV treatment: 3 by 5 initiative', Geneva: World Health Organization.

Maluka, S., Kamuzora, P., San Sebastiån, M., et al. (2010) 'Decentralized health care priority-setting in Tanzania: evaluating against the accountability for reasonableness framework', Social science \& medicine, 71(4), pp. 751-759.

Maluka, S., Kamuzora, P., San Sebastián, M., et al. (2010) 'Improving district level health planning and priority setting in Tanzania through implementing accountability for reasonableness framework: perceptions of stakeholders', BMC health services research, 10(1), p. 322.

Maluka, S. et al. (2011) 'Implementing accountability for reasonableness framework at district level in Tanzania: a realist evaluation', Implementation Science, 6, p. 11. doi: 10.1186/1748-5908-6-11.

Maluka, S. O. (2011) 'Strengthening fairness, transparency and accountability in health care priority setting at district level in Tanzania', Global Health Action, 4(1), p. 7829.

Metz, T. (2007) 'Toward an African moral theory', Journal of Political Philosophy, 15(3), pp. 321-341.

Metz, T. and Gaie, J. B. R. (2010) 'The African ethic of Ubuntu/Botho: implications for research on morality', Journal of Moral Education, 39(3), pp. 273-290. doi: $10.1080 / 03057240.2010 .497609$.

Moosa, M. R. et al. (2016) 'Use of the "accountability for reasonableness" approach to improve fairness in accessing dialysis in a middle-income country', PLoS One, 11(10), p. e0164201.

Mshana, S. et al. (2007) 'What do District Health Planners in Tanzania think about improving priority setting using'Accountability for Reasonableness'?', BMC Health Services Research, 7(1), p. 180.

Neumann, P. J. et al. (2008) 'A strategic plan for integrating cost-effectiveness analysis into the US healthcare system.', The American journal of managed care, 14(4), pp. 185-188.

Patel, A. D. (2017) 'A world of difference between private and public healthcare in south africa - Google Search', The Daily Vox, 3 August. Available at: https://www.google.ca/search?rlz=1C1CHBF_enCA761CA762\&biw=1013\&bih=945\&ei=Wac6Wo-

sFovYjwTenYiYDQ\&q=a+world+of+difference+between+private+and+public+healthcare+in+south+africa\&oq=a+world+of+difference+between+private+and+p ab.3...200473.222941.0.223430.81.64.3.12.12.0.353.8205.6j34j8j2.50.0....0...1c.1.64.psy-

ab..16.49.5509...0j0i67k1j0i131k1j0i10k1j0i22i30k1j33i22i29i30k1j0i13i30k1j33i21k1j33i160k1.0.e-bf_oo-y-o (Accessed: 20 December 2017).

Peabody, J. W. (1996) 'Economic reform and health sector policy: lessons from structural adjustment programs', Social Science \& Medicine, 43(5), pp. 823835.

Pettigrew, L. M. and Mathauer, I. (2016) 'Voluntary Health Insurance expenditure in low-and middle-income countries: Exploring trends during 1995-2012 and policy implications for progress towards universal health coverage', International journal for equity in health, 15(1), p. 67.

Rawls, J. (2001) Justice as fairness: A restatement. Harvard University Press.

Riddell, J. B. (1992) 'Things fall apart again: structural adjustment programmes in sub-Saharan Africa', The Journal of Modern African Studies, 30(1), pp. 5368 .

Shutte, A. (2009) 'Ubuntu as the African Ethical Vision', in Murove, M. F. (ed.) African Ethics: An Anthology of Comparative and Applied Ethics. University of Kwazulu-Natal Press, pp. 85-99.

Tangwa, G. B. (2001) 'Moral agency, moral worth and the question of double standards in medical research in developing countries', Developing world bioethics, 1(2), pp. 156-162.

Tangwa, G. B. (2002) 'The HIV/AIDS pandemic, African traditional values and the search for a vaccine in Africa', The Journal of medicine and philosophy, 27(2), pp. 217-230.

Tangwa, G. B. (2017) 'Giving voice to African thought in medical research ethics', Theoretical medicine and bioethics, 38(2), pp. 101-110.

Tosam, M. J. et al. (2017) 'Global health inequalities and the need for solidarity: a view from the Global South', Developing World Bioethics, 0(0). doi: 10.1111/dewb.12182.

Tutu, D. (2000) No Future Without Forgiveness. New York: Image.

Ujewe, S. J. (2012) Ought-onomy and African health care: Beyond the universal claims of autonomy in bioethics. University of Otago.

Ujewe, S. J. (2016) Just Health Care in Nigeria-The Foundations for an African Ethical Framework. University of Central Lancashire.

Ujewe, S. J. (2019) 'Why Justice is Good for Healthcare in Africa: Towards an Ethical framework', in Socio-cultural Dimensions of Emerging Infectious Diseases in Africa. Cham: Springer, pp. 255-267. 
Van Damme, W., Kober, K. and Laga, M. (2006) 'The real challenges for scaling up ART in sub-Saharan Africa', Aids, 20(5), pp. 653-656.

Van Staden, Cornelius and Fulford, K. (2015) 'The Indaba in African Values-Based Practice: Respecting Diversity of Values without Ethical Relativism or Individual Liberalism', in Sadler, J. Z., Fulford, K. W. M., and Van Staden, CW (eds) The Oxford Handbook of Psychiatric Ethics. Oxford: Oxford University Press, pp. 295-318.

WHO (2020) World Health Statistics 2020: Monitoring Health for the SDGs, Sustainable Development Goals. Geneva: World Health Organization.

World Health Organization (2004) 'Guidance on ethics and equitable access to HIV treatment and care', Geneva: WHO.

Writer, S. (2017) 'South Africa's cheapest medical aid schemes and hospital plans in 2017', BusinessTech, 4 May. Available at:

https://businesstech.co.za/news/lifestyle/173415/south-africas-cheapest-medical-aid-schemes-and-hospital-plans-in-2017/ (Accessed: 20 December 2017).

Yu, J. K.-L. et al. (2007) 'True outcomes for patients on antiretroviral therapy who are" lost to follow-up" in Malawi', Bulletin of the World Health Organization, 85(7), pp. 550-554. 